\title{
The comparison of PCA and discrete rough set for feature extraction of remote sensing image classification - A case study on rice classification, Taiwan
}

\author{
T. C. Lei · S. Wan · T. Y. Chou
}

Published online: 5 August 2008

(C) Springer Science + Business Media B.V. 2008

\section{Erratum to: Comput Geosci (2008) 12:1-14 DOI: 10.1007/s10596-007-9057-7}

Unfortunately, due to the improper extraction of samples, the Table 4 has to be modified as the following:

Table 4 The image classification accuracy of two difference knowledge methods (Original Paper of Table 4, of revised )

\begin{tabular}{|c|c|c|}
\hline & $\begin{array}{l}\mathrm{PCA}+ \\
\operatorname{RSKC}(\%)\end{array}$ & $\begin{array}{l}\text { Discrete rough } \\
\text { set + RSKC (\%) }\end{array}$ \\
\hline 1. Percentage from paddy rice & 47.00 & 47.67 \\
\hline 2. Percentage from non-paddy rice & 39.67 & 46.33 \\
\hline \multicolumn{3}{|l|}{ 3. Omission error: } \\
\hline Paddy rice & 6.00 & 4.67 \\
\hline Non-paddy rice & 20.67 & 7.33 \\
\hline \multicolumn{3}{|l|}{ 4. Commission error: } \\
\hline Paddy rice & 18.02 & 7.14 \\
\hline Non-paddy rice & 7.03 & 4.79 \\
\hline 5. Overall accuracy result & 86.67 & 94.00 \\
\hline 6. Overall inaccuracy result & 13.33 & 6.00 \\
\hline
\end{tabular}

The online version of the original article can be found at http://dx.doi.org/10.1007/s10596-007-9057-7.

T. C. Lei $(\varangle) \cdot$ T. Y. Chou

GIS Center, Feng Chia University,

No. 100 Wenhwa Rd., Seatwen,

Taichung, Taiwan 40724, Republic of China

e-mail: tclei@fcu.edu.tw

S. Wan

Department of Information Management,

Ling Tung University, No.1 Ling Tung Road,

Taichung, Taiwan, Republic of China

e-mail: Shiuan123@mail.ltu.edu.tw
The reason for modifying this Table is the original percentage for PCA + RSKC and Discrete Rough Set + RSKC stemmed from different base data. More specifically, the original paper the case for PCA + RSKC is using 150 (paddy rice) +150 (non-paddy rice) and Discrete Rough Set + RSKC is using 110 (paddy rice) + 190(non-paddy rice). This is inappropriate for expression. The new Table is generated by using equal samples of paddy rice and no-paddy rice in both cases. That is, PCA + RSKC is using 150 (paddy rice) + 150 (nonpaddy rice) for PCA + RSKC and PCA + RSKC is using 150 (paddy rice $)+150($ non-paddy rice $)$. 